\title{
Using a Reflective Practice Model to Teach STEM Education in a Blended Learning Environment
}

\author{
Areej ElSayary ${ }^{1 *}$ \\ ${ }^{1}$ Zayed University, UNITED ARAB EMIRATES
}

Received 23 November 2020 - Accepted 5 February 2021

\begin{abstract}
This study explores and explains teachers' perceptions and practices in using a reflective practice model to teach STEM education in a blended learning environment. The study was conducted before the COVID-19 lockdown and continued after the quarantine till the end of the semester. The transformative learning and the experiential learning theories are used as combined conceptual frameworks to form a reflective practice model that guided this study. The participants are middle school teachers $(n=18)$ in a private school in the United Arab Emirates UAE. A sequential mixed-method approach using quantitative and qualitative data was used. An online survey with closed-ended items was adopted to collect quantitative data from teachers. The qualitative data was collected through teachers' semi-structured interviews using Zoom conference meeting. The study's results reveal that teachers' perceptions and practices about learning and skills needed in the future will be different from before COVID-19.
\end{abstract}

Keywords: blended learning, experiential learning, STEM curriculum, transformative learning

\section{INTRODUCTION}

The reform of the education system in the United Arab Emirates UAE is one of the main goals of the country's National Agenda (UAE, 2009). Having a higher percentage of high-quality teachers is one of the UAE's 2030 Agenda's key performance indicators for sustainable Development (2017). The norm of education in the UAE is face-to-face, blended, and online, supported by e-learning platforms. In response to the COVID-19 pandemic, the lockdown of schools and universities took place in March 2020, and a shift toward online learning was planned and implemented (Dubai Future Foundation, 2020). This happened after spending almost half of the semester in schools. In order to change the system proactively, regulatory bodies began setting up transformative changes to develop innovative solutions for schools (Dubai Future Foundation, 2020). Schools and universities across the UAE adopted different communication platforms such as Zoom, Microsoft Teams, Adobe Connect, etc. The untimely closure of schools and universities led to changing the learning plans to fit the remote learning. Then, more plans about the implementation of blended learning in schools and universities took place. There is currently little literature on COVID-19 concerning the educational studies and its impact on transforming students' learning and educators' perspectives about the shape of learning in the future. Many questions have been raised about learning and working after COVID-19, competencies needed for future jobs, social/emotional development of students, the job market needs, and even more than these were discussed in seminars.

Enabling students to acquire the competencies needed to be successful citizens is one of the UAE's main purposes. However, the link between the education sector and the job demands is very weak due to the fact that more than $50 \%$ of Emirati students choose the humanities fields rather than science fields (Hvidt, 2016). A previous study that argued the UAE STEM workforce shortage stated that only $21 \%$ of students in government universities enrolled in STEM majors (Moonsear et al., 2015). Of the students who enrolled in STEM majors, $31 \%$ were studying engineering, and $61 \%$ were studying natural science; within this, a minority were females, and the majority were males (Moonsear et al., 2015). A particular focus is on developing vocational and technical education and revamping the curricula where critical thinking, creativity and innovation, and problem-solving are outcomes of learning (Alfaki, 2015).

(C) 2021 by the authors; licensee Modestum. This article is an open access article distributed under the terms and conditions of the Creative Commons Attribution License (http://creativecommons.org/licenses/by/4.0/).

$\square$ areej.elsayary@zu.ac.ae (*Correspondence) 


\section{Contribution to the literature}

- This study explains and explores teachers' perceptions and practices using the reflective practice model in the blended learning approach after COVID-19.

- The reflective practice model is developed to combine experiential and transformative learning processes. Experiential learning was used to plan a STEM learning environment that includes challenges and complex real-life problems. The transformative learning process is used as checking points of reflection and feedback.

- The study highlights how the lockdown changes educators' perspectives and plans in education after COVID-19.

- The study proposes suggestions for future research about the impact of these changes on the education system.

As a result, secondary school curricula in the emirate of Abu Dhabi have been reformed to focus on STEM subjects in 2015 (Moonsear et al., 2015). In addition, the UAE Science, Technology, and Innovation Policy established in November 2015 stated that increasing Emirati participation in the STEM workforce is one of the important pillars that should be considered for the development of a knowledge-based economy (UAE Government, 2015).

The emergence of remote teaching and learning happened due to the lockdown of COVID-19 placed students and teachers in uncomfortable situations. The transformative learning theory proposed by Meizrow (1997) focuses on the process of changing an individuals' frames of reference through reflection, active learning, and placing ourselves in uncomfortable situations. This allows students to develop their understanding of the world and themselves where a potential change to their perspectives and frames of reference occurred.

On the other side, experiential learning theory developed by Kolb (1984) provides direction on designing programs that include more hands-on activities. It is a philosophy that requires students to be engaged in direct experience and focused reflection to construct knowledge (Ochsner \& Hall, 2019). Experiential learning applications include different learning forms by doing, such as project-based learning, problem-based learning, and inquiry-based learning (Ochsner \& Hall, 2019). Students experience the learning cycle of experiential learning (DO, OBSERVE, THINK, and PLAN).

Strange and Gibson (2017) pointed out that combining transformative and experiential learning to design and assess effective programs can promote concrete learning. In this learning environment, students were taken out of their comfort zone of face-to-face learning to online learning and apply the basis of experiential learning to the potential outcomes of transformative learning. Since the purpose and outcomes of the transformative and experiential learning are in alignment, it is appropriate to combine them (Strange \& Gibson, 2017) as a reflective practice model to guide this study. The reflective practice model merges between the experiential and transformative learning processes to guide teachers' planning and teaching of the STEM curriculum. STEM curriculum tends to be an innovative curriculum that requires learning by doing (ElSayary et al., 2015).

Students need to have many checking points throughout the learning process, where they should receive feedback and reflect on their learning. In order to transform students' learning, three main components need to be considered: the design of an integrated STEM curriculum, the cycle of experiential learning, and feedback and reflection on every aspect of learning (Ochsner \& Hall, 2019). It was stated in previous studies that the use of experiential learning with an integrated STEM curriculum leads to transforming students' habits of mind (Greenhill et al., 2018).

The purpose of this study is to explore and explain teachers' perceptions and practices of using a reflective practice model in planning and teaching STEM education in a blended learning approach. According to the literature presented, the following questions are used to guide this study:

1. What are the teachers' perceptions about using the reflective practice model to plan and teach an integrated STEM curriculum?

2. How do the reflective model influence teachers' instructional practices?

\section{STEM Curriculum}

STEM is a curriculum used to prepare learners with higher-order abilities and habits of mind to deal positively and productively with the global challenges and complex problems they might face (Taylor, 2016). STEM increases students' engagement and understanding to become the science and technology leaders in an experiential learning environment (So, et al., 2018). This is the thinking through the materials, which is considered STEM practices where learners are able to make connections between the disciplines (Guyotte, et al., 2014).

There are many ways that STEM can be taught in schools that vary based on different ways of integrating 
STEM disciplines. The lowest level of integration between two or more disciplines is called multidisciplinary (S-T-E-M), where the topic is explained from different perspectives of multiple disciplines (Dugger \& Fellow, 2011; Repko, 2008). The next level is called interdisciplinary (SteM), where there is an overlapping of concepts, and knowledge is shared in more depth using different disciplines to focus on problem-solving (Dugger \& Fellow, 2011; Repko, 2008). The highest level of integration is the transdisciplinary (E $\rightarrow$ STM), where there is blurry between the disciplines' boundaries that are integrated below on the main subject (Dugger \& Fellow, 2011; Repko, 2008). Beane (1991) criticized the multidisciplinary and interdisciplinary and emphasized the important use of the transdisciplinary due to its impact on transforming students' learning. STEM education can transform students' perspectives, change their habits of mind, and suit different interests when appropriate pedagogies, use of technology as a tool, and contents are intertwined (ElSayary, 2020).

So et al. (2018) emphasized the importance of planning and teaching STEM using an experiential learning environment as a process to design activities and guide students' learning, while transformative learning is set to assess, evaluate and check students learning where they have the opportunities to reflect on their learning, receive feedback, and improve their work (Strange \& Gibson, 2017).

\section{Experiential Learning}

Experiential learning is a theory of education that builds on social and cognitive constructivism theories of learning. Beard and Wilson (2006) explained experiential learning as the active process and engagement between the inner world of learners and the outer world of the environment. Kolb (1984) stated that true knowledge is created through learners' experiences; however, Dewey (1938) pointed out that investigative learning transforms feelings and attitudes to purposeful actions whereby learners learn by reflecting on their own experiences. Dewey (1933) stated the importance of enriching possibilities of experiences to change learners' ways of viewing the world and how to be in a transformative world.

Kolb (1984) has introduced a model for experiential learning to include four elements: DO (concrete experience), OBSERVE (observation and reflection), THINK (the formation of abstract), and PLAN (trying out what you have learned and applying it in new situation). This model allows students to develop their skills, such as collaboration, communication, critical thinking, creativity, problem-solving, and metacognition. For teaching STEM curriculum, experiential learning can be suitably used in different authentic forms such as problem-based, project-based, and inquiry-based learning, where they include the four elements of Kolb's (1984) model. It was stated that experiential learning occurs through constructed feedback, opportunities for students' reflection, apply and solve problems, and demonstration of learning (Ochsner \& Hall, 2019). The process of this pedagogy requires integrated knowledge where it has a positive impact on transforming students' learning (Greenhill et al., 2018). It allows for flexibility and differentiation of students' learning as they can learn different content based on their interests in a real-life context (Cheng, 2015). Teachers need to design instructional activities framed as ongoing inquiry (Almqvist, et al., 2017) which allow students to be self-reflective, independent, and critical thinkers (Li et al., 2019). This allows students to be prepared for jobs that do not yet exist. Experiential learning is meaningful for students; however, there are significant challenges for things to go wrong unpredictably and threaten students' opportunities to demonstrate their capabilities. Therefore, the merging of transformative learning to the experiential learning process is important as it sets as an assessment tool of students' learning (Strange \& Gibson, 2017).

\section{Transformative Learning}

Mezirow (1997) pointed out that a transformation of students' learning happens when changes in their frame of reference occurs, including points of view and habits of mind. Change in the points of view comes through transforming individuals' beliefs, value judgments, and attitudes. It is easy to change because it is based on empirical evidence. In contrast, habits of mind are how learners think, feel, and act in the world. It is not easy to change because it needs learners to go through a reflective thinking process (Mezirow, 1997).

The process of transforming learning theory involves transforming frames of reference through critical reflection on assumptions, validating contented beliefs through discourse, taking actions on one's reflective insight, and critically assessing it (Mezirow, 1997). Critical reflection refers to the self-examination and awareness of others (Owen, 2016). It is used in the sense of questioning and brainstorming how and why we think specific things in certain ways (Cranton \& Carusetta, 2004). In other words, it is the purposeful critical analysis of knowledge and experiences that allows learners to achieve more profound meaning and understanding (Mann et al., 2007; Owen, 2016). Dewey (1934) emphasized the role of reflection that enriches the possibility of experience that changes learners' relationship with the world, a new way of viewing the world, and a new way to exist in the world that is transformative. The critical reflection took place in the process of observation and reflection, where students have engaged actively on a task over a long period (Sipos et al., 2008).

Rational Discourse refers to meaningful communications with others in the process of specific 


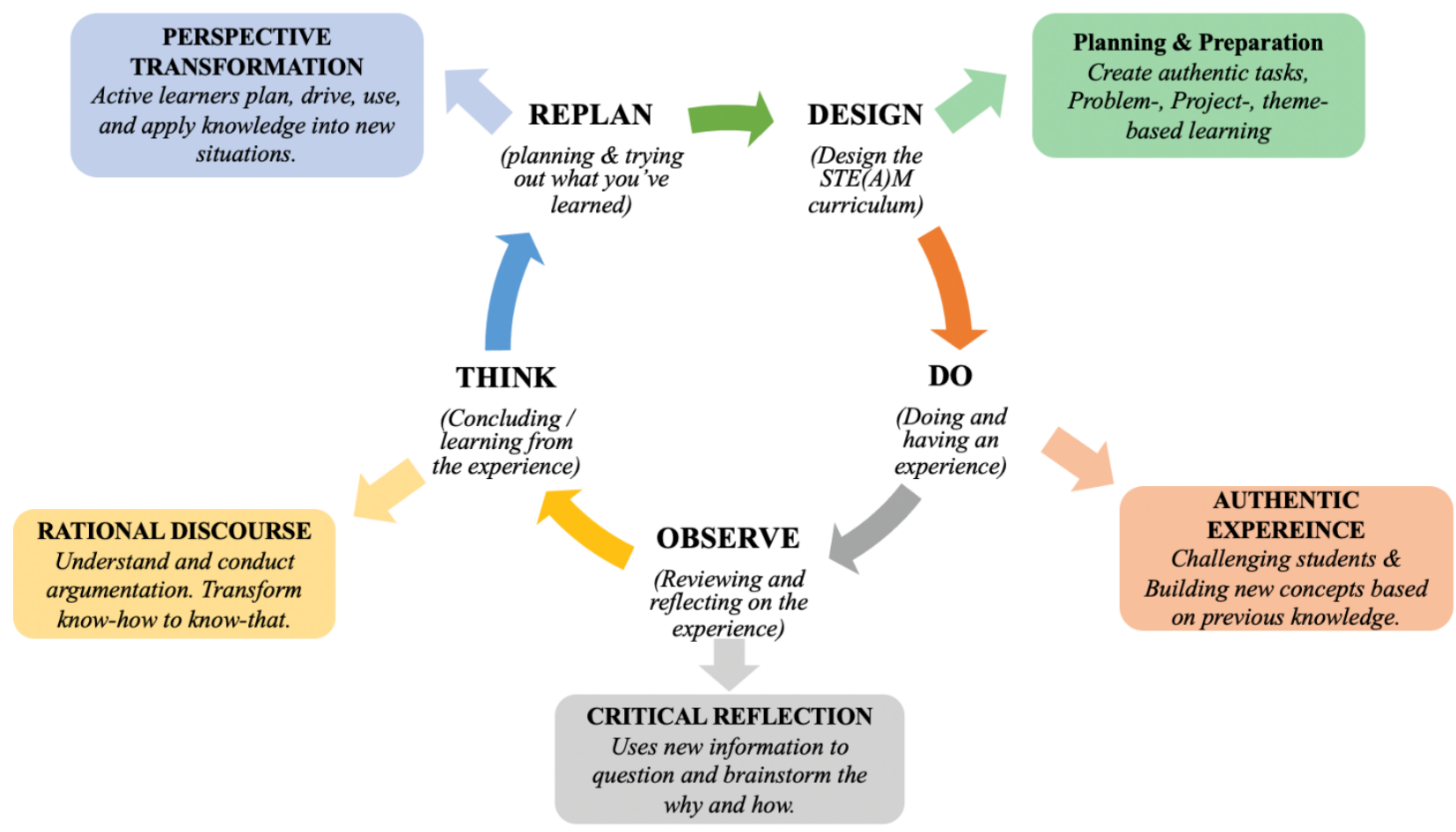

Figure 1. The reflective practice framework was developed that integrates experiential learning with the transformative learning processes adapted from Strange and Gibson (2017)

dialogue intended to validate an individual's experiences and ideas (Mezirow, 1997). The critical reflection and discourse lead to the third stage, which is transforming the perspective (Provident et al., 2015). This is aligned with Dewey (1907), Freire (1970), and Knowles (1980), who promoted pedagogies that allow students to be active learners who drive and use knowledge rather than receive it. Therefore, skills such as motivation, self-discipline, and self-direction are essential in order to be successful learners.

Transformative learning theory has been applied to adults as it was assumed that children are not able to experience and critically reflect on their learning that leads to transformation (Merriam, 2004; Taylor, 2007). However, research has proved that transformative learning theory is more effective when it is started with children at a young age as they are capable of being selfregulated regarding their learning, having curiosity that motivates them to be engaged, and reflect critically on their learning (National Research Council, 2000; Singleton, 2015).

\section{REFLECTIVE PRACTICE MODEL}

The developed framework requires integration between the process of experiential learning and transformative learning theories (Strange \& Gibson, 2017) used to guide this study. Problem-based, projectbased, and inquiry-based learning are types of experiential learning used to plan and teach STEM curriculum, while transformative learning is used as a guide to teach the STEM curriculum in more depth and evaluate potential outcomes of students' learning. Figure
1 illustrates the framework used as a process where there is an integration between experiential learning and transformative learning. The process starts by designing the curriculum and planning it using theme-based, project-based, or problem-based learning. Then, engage students in STEM education and authentic experience to build new concepts based on their previous knowledge. They learn by doing and gaining experiences of what they learn. The third stage is to observe, review what they experienced, and critically reflect on how and why they construct their knowledge. The fourth stage is abstract thinking, where they conclude learning from the experience they gained through understanding and conducting argumentation. They are engaged in a rational discourse where they understand the concepts in more depth, conduct argumentation to defend their ideas, and transform know-how to know-that. The last stage is replanning and transforming what they have learned into a new situation where they transform their frame of reference and be active learners who use and drive knowledge to plan and apply it into new situations.

\section{METHODOLOGY}

This study employed a sequential mixed method to extend the breadth and depth of different inquiry methods (Creswell, 2014). In order to understand the phenomenon, it was suggested to collect multiple data (qualitative and quantitative) that allow integrating the results (Creswell, 2014). This is based on the philosophy of pragmatism (Johnson \& Christensen, 2014). The rationale of using quantitative and qualitative data is to 
seek development of the results from one method with the results of the other method. This includes sampling and implementation.

The reflective practice model is developed to enhance planning and implementing the STEM curriculum for middle school students. The research supervisor guided the curriculum developers and teachers on using the reflective practice model to plan and teach STEM subjects and projects. The use of this model is helping the school in developing new goals to achieve in the school strategic plan.

\section{Participants}

The participants of the study are middle school teachers from a private school in UAE with five campuses. As the five campuses follow the same system of curriculum planning, two campuses were selected randomly to conduct the study. In elementary, the homeroom teachers are specialized in general education, and early childhood not specialized in specific subjects and have zero to five years of teaching experiences. Accordingly, the elementary teachers were not selected to participate in the study. In middle and high school, teachers are specialized in science, technology, engineering, and math. Due to the lockdown of the COVID-19, the school administration replanned the high school curriculum to focus on the main subjects and prepare students for the standardized assessments with less focus on STEM projects. However, the replanning of the middle school curriculum has no major impact on teaching STEM projects. Accordingly, the middle school teachers were selected to participate in this study.

The population of the teachers is $\mathrm{N}=56$ from the two campuses who participated in the study. All teachers attended the training during the induction weeks at the beginning of the semester. The intended sample size was 20 teachers; however, the participants who did not meet the criteria were excluded from the study. The criteria set for the participants was defined by (i) should be specialized in chemistry, biology, physics, technology, mathematics or engineering, (ii) having five years teaching experience or more in their professional area of expertise, (iii) having a degree in education. The final sample $(n=18)$ was selected purposively from teachers who met the criteria from the two campuses to do the survey. Of the participants in the sample, $66.7 \%(n=12)$ were females and $33.3 \% \quad(n=6)$ were males. After completing the survey, an email was sent to participants to thank them for their participation and asking if they would like to participate in the interview to share further details about their experiences in using the reflective practice model in a blended learning environment. Thirteen teachers replied to the email to participate in the interview. Six were selected purposefully for the interview to have equal numbers of males and females from those teachers. The selected participants for the interview were two teachers from each specialization (math, science, and technology). As the teachers who participated in the survey included a higher number of females than males, an equal number of genders were considered in the interview.

\section{Instrumentation}

A survey is used to collect quantitative data from the teachers about their practices using the reflective practice model to teach STEM subjects in a blended learning approach. The survey consisted of two main sections: demographic information where the criteria were set, and five sub-sections of the reflective practice model stages. For teachers' demographic information, multiple-choice questions were used. A five-point Likert scale was used to measure teachers' practices in using the reflective model. Each item in the five sub-sections featuring the following response choices: 5=Strongly agree, 4=agree, 3=neutral, 2=disagree, 1=strongly disagree. The items distributed with each sub-section are as follows: planning and preparation (6 items), authentic experience (5 items), critical reflection (6 items), rational discourse (5 items), and perspective transformation (6 items). The five sub-sections were designed after reviewing the previous literature related to the experiential learning process (Kolb, 1984; Ochsner \& Hall, 2019) and transformative learning approach (Greenhill et al., 2018; Li et al., 2019; Mezirow, 1997; Singleton, 2015). The total items of the survey (five subsections) consisted of 28 items. The survey was given to five specialists in science, technology, and mathematics education. They were asked to give their opinions on: (i) the suitability of the instrument in achieving the purpose of the study, (ii) whether the items were appropriate to each sub-section to which they belonged, (iii) accuracy of the language used. Suggestions received from experts were about rewording some items, removing two items, and changing the placement of some items. Based on the feedback received, some items were modified, and two items from the perspective transformation sub-section were removed to form a total of four items instead of six items. Accordingly, the final version of the survey (five sub-sections) consisted of 26 items. Regarding the instrument reliability, the internal consistency coefficient (Cronbach's Alpha) was used. The reliability coefficient for the sub-sections was between $0.86-0.9$, which is considered suitable for the study. After assuring the reliability of the instrument, the survey was administered to the teachers through a web-survey. A descriptive statistic was used to analyze the survey results to include mean and standard deviation.

The interview protocol was developed by the researcher where it comprises five semi-structured questions. The questions were given to two experts in mathematics and science education to determine the face validity and clarity. The experts agreed on four questions and suggested changes in the first question. Thus, the first question was changed accordingly. The 
Table 1. Handal et al.'s (2013) Questionnaire score range

\begin{tabular}{lc}
\hline Score Range & Description \\
\hline $1.0 \leq x<1.5$ & Very low \\
$1.5 \leq x<2.0$ & Low \\
$2.0 \leq x<2.5$ & Moderately low \\
$2.5 \leq x<3.0$ & Slightly below average \\
3.0 & Average \\
$3.0<x \leq 3.5$ & Slightly above average \\
$3.5<x \leq 4.0$ & Moderately high \\
$4.0<x \leq 4.5$ & High \\
$4.5<x \leq 5.0$ & Very high \\
\hline
\end{tabular}

final version of the instrument was piloted with a math teacher, and her positive comments were noted. Then, no further changes were made from the final version. The questions aimed to explain how the STEM process impacted students' learning, their engagements and experiences in online learning, how they argued and defended their points of view, and the plans for further improvements.

\section{Procedure}

The consent forms were sent to participants at the beginning of the study and a full explanation of the purpose was provided. The data was collected sequentially, started by the quantitative data of the survey and followed by the qualitative data of the interview.

The survey is designed to address the first question of the study: what are the teachers' perceptions about using the reflective practice model to plan and teach an integrated curriculum? Teachers used the reflective practice model in planning, teaching, and assessing STEM during the semester. The survey was sent to them through a web-survey link to understand and explain their perceptions and practices about using the reflective practice model in terms of the planning and preparation, authentic experience, critical reflection, rational discourse, and perspective transformation. A descriptive statistic was used to present the mean and standard deviation. The researcher used Handal et al. (2013) questionnaire score range of the means to explain the results.

The semi-structured interview was conducted after completing the survey to address the second question of the study: how does the reflective practice model influence teachers' instructional practices? The interview was conducted with five open-ended questions to understand in-depth the influence of the reflective practice model on teachers' instructional practices in online learning. Interviews were held for 30 to 40 minutes with an average interview time of 38 minutes. The results were analyzed using the phenomenological approach to describe the teachers' experiences of using the reflective practice model and how it influenced their instructional practices.

The results of both data were represented separately and merged in the discussion section to fulfill the main purpose of the study which is to explore and explain teachers' perceptions and practices of using a reflective practice model in planning and teaching STEM education in a blended learning approach.

\section{RESULTS}

\section{Teachers' Survey Results}

The survey was conducted at the end of the semester to understand teachers' perceptions about using the reflective model. After spending half of the semester on campus, schools and universities were requested to close and complete their study online. Accordingly, teachers had to change the plans to be suitable for online learning settings. The data of the survey is categorized based on the framework of the study. Figure 2 shows a

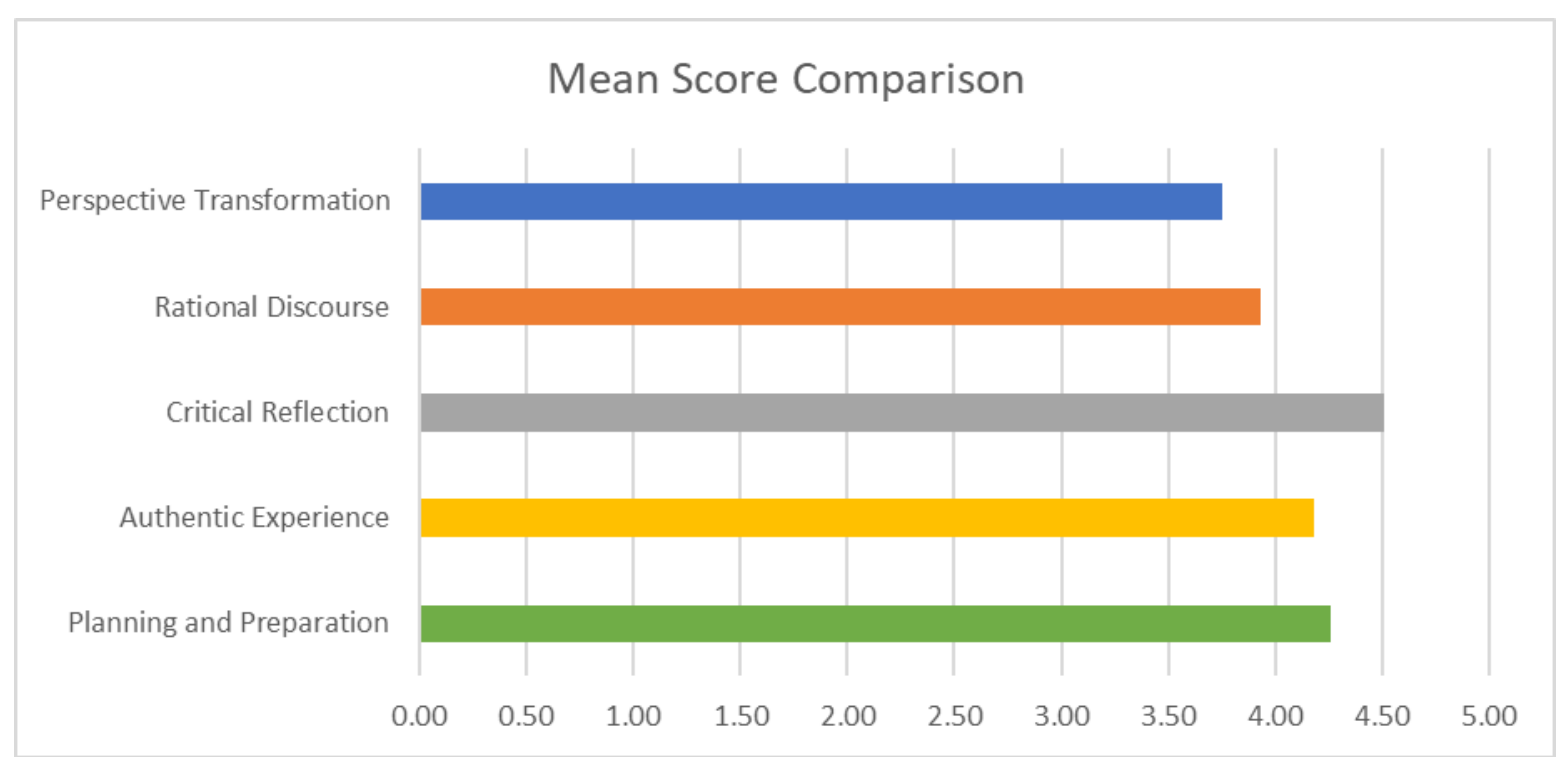

Figure 2. Comparison between the means of the five stages of the reflective practice framework 
Table 2. The mean and standard deviation of the Questionnaire results

Planning and Preparation

1. Using technology to plan and teach integrated contents (e.g., iClouds apps, google apps, AR apps, etc.)

2. Challenging students by complex real-world problems.

3. Integration between disciplines allows for more concepts that can be taught in less time and in higher levels

4. Students develop projects related to their interest

5. Planning experiential learning tasks and lessons (such as problem-, project- or theme-based).

6. Playing the role of a facilitator.

Authentic Experience

1. Students presented solutions of real-world problems

2. Students were able to try things out for themselves

3. Students organize the class concepts into a meaningful format.

Mean SD

4. Students thought of how the class concepts were interrelated.

$4.06 \quad 1.06$

$\begin{array}{ll}4.06 & 0.94\end{array}$

$4.56 \quad 0.51$

5 . Core concept of math and science are easy to teach online.

$4.22 \quad 0.65$

$\begin{array}{ll}4.17 & 0.62\end{array}$

$4.5 \quad 0.51$

Critical Reflection

1. Students compared information from different sources before completing a task or assignment

$4.5 \quad 0.62$

$\begin{array}{ll}4.56 & 0.51\end{array}$

$\begin{array}{ll}4.56 & 0.51\end{array}$

$\begin{array}{ll}4.5 & 0.51\end{array}$

$2.78 \quad 1.26$

2. Students summarized or created their own interpretation of what they have read or been taught

$4.56 \quad 0.62$

$\begin{array}{ll}4.56 & 0.51\end{array}$

3. Students analyzed competing arguments, perspectives or solutions to a problem

$\begin{array}{ll}4.83 & 0.38\end{array}$

4. Students drew conclusions based on analysis of relevant information

3.720 .75

5. Students developed a persuasive argument based on supporting evidence or reasoning

$\begin{array}{ll}4.62 & 0.5\end{array}$

6. Students used the feedback to solve complex problems or answer questions that have no single correct

$\begin{array}{ll}4.78 & 0.43\end{array}$ solution or answer

Rational Discourse

1. Students decided how they will present their work or demonstrated their learning using different

$4.17 \quad 0.62$ resources

2. Students made intentional selection of the tools, products, or designs to communicate their ideas

$3.78 \quad 0.94$

3. Students had the choice to use the STEM laboratory.

$2.78 \quad 1.26$

4. Students argue their points of view and answer questions in front of audiences

$4.28 \quad 0.67$

5. Students prepared and delivered an oral presentation to the teacher or others virtually

$\begin{array}{ll}4.17 & 0.71\end{array}$

Perspective Transformation

1. Students planned the steps they take to accomplish a complex task

$\begin{array}{ll}4.39 & 0.61\end{array}$

2. Students monitored their own progress towards completion of their task and modify their work accordingly

3. Students are provided with information regarding STEM university majors and career.

3.390 .98

4. Students had the opportunity to meet with industry partners involved in STEM careers.

$3.56 \quad 0.98$

comparison between the means of the categories. The mean scores of the rational discourse (mean=3.93) and perspective transformation (mean=3.75) were moderately high, while the mean scores of critical reflections (mean=4.51), authentic experience $($ mean $=4.18)$, and planning and preparation $($ mean=4.26) were high.

The result of the survey is analyzed and categorized in Table 2 as: planning and preparation, authentic experience, critical reflection, rational discourse, and perspective transformation. The results show that the mean scores of two items were slightly below average: teaching core concepts of math and science are easy to teach (mean=2.78), and students had the choice to use STEM laboratory (mean=2.78).

Moreover, the mean score of the item: students are provided with information regarding STEM university majors and career (mean=3.39) was slightly above average. Three other items that were moderately high are: students drew conclusions based on analysis of relevant information (mean=3.72), students made intentional selection of the tools, products, or designs to communicate their ideas (mean=3.78), and students had the opportunity to meet with industry partners involved in STEM careers (mean=3.56). The mean scores of all other items were ranged between high and very high.

\section{Teachers' Interview Results}

Due to the lockdown of the quarantine, teachers were interviewed virtually using Zoom conference. Their responses were categorized based on the questions presented in the interview using the framework of the study.

\section{Q1: How does the process of STEM projects have an impact on students' learning?}

All teachers during the interview agreed about the same process used in the reflective practice model. Students start by identifying the problems, finding solutions for the problems, formulate research questions, planning for their projects, creating models and prototypes, and reflecting on their work. When the 
students tried to find solutions for the problems, they think divergently where each is looking for the solution that led to creating a project based on their interests. During project planning, the teachers guided them and placed them in homogenous groups based on their interests to create the projects. Then, students created their projects and did experiments or tested the prototypes. The last stage is the evaluation, where students did self-evaluation, provided feedback to their peers, and listened to teachers' feedback. They improved their work based on the reflection and feedback received. During each stage in the project, students had the opportunity to reflect on their work, argue, and defend their points of view. One of the teachers responded,

\begin{abstract}
"STEM projects improved students' learning skills through creating dynamic learning environments and extending their thinking to real-life problems. In addition, it enhances students' creativity, collaboration, communication, and self-direction skills."
\end{abstract}

\section{Q2: Describe the students' engagements in their STEM projects after the quarantine.}

All teachers interviewed agreed that the lockdown impacted students' negatively in the first few weeks. However, the school had to restructure the curriculum and adjust their annual plans to suit blended learning. Below is a response from one of the teachers.

\section{T1: The students are hardly engaged in STEM projects after the quarantine. Only a few students who were interested in the project were highly engaged.}

Although the school utilized many technological resources, some students find difficulty staying on task. This was during the first weeks after the lockdown. However, all teachers emphasized that learning in online settings has a different shape and way of implementation. They all emphasized that students had to be responsible for completing their work on time. They also said that technology allowed them to deepen their learning and use simulators, creating apps, etc. One teacher said:

"STEM projects raised students' engagement and helped them to deepen their learning, be responsible and self-directed learners to research, solve problems, find alternative solutions and communicate with other experts via Zoom, Skype, Schoology, etc."

Another teacher stated,

$$
\begin{aligned}
& \text { "students presented their projects virtually and instead } \\
& \text { of using journals to record their ideas they used e- } \\
& \text { portfolios that were very effective in supporting their } \\
& \text { projects ideas." }
\end{aligned}
$$

Q3: Explain how you find students' experience in the online learning offered.

All teachers pointed out that the learning pace was slower than before; however, this showed the gaps in students' independent skills. They emphasized the robust correlation between students' learning and the use of technology. The higher skills they have in information technology, the higher engagement in learning occurs. They emphasized that this was a noticeable difference found in their teaching strategies as well. One of the teachers' quotes is listed below.

\section{T2: Students excel in technology use and are interested in the platform, especially that the newly implemented platform supports learning with many features used.}

All teachers emphasized that this new experience made students excel in online learning and be more responsible. They all believed that it is important to develop students' digital competencies in this era.

\section{Q4: How do students argue and defend their ideas of STEM problems/projects in a blended learning environment?}

Teachers stated that they schedule timing for students (individual/group) to argue and defend their ideas. Teachers use breakout rooms on Zoom where they can meet with each group to present their projects and share ideas, reflect on their work, and have the opportunity to improve their final products. Other students preferred to record videos explaining and defending their points of view. Then, they meet with students virtually on Zoom conference. Teachers provide students with constructive feedback to improve their work. Students improve their projects for the final presentations. In the final presentations of the projects, the school conducts a virtual fair day with different Zoom sessions for each grade-level where students present their works and attendees vote for their projects.

A teacher mentioned that:

\footnotetext{
"The blended learning approach is a differentiated learning environment where learners can meet their individual needs and goals in addition to finding strong evidence that supports their arguments."
}

Teachers added that they need to restructure their learning activities to include more resources and provide students with mobile learning tools to support their projects.

\section{Q5: What are the future plans you will consider for further improvements?}

Some teachers believed that more training is needed for them and for students about the efficient use of the learning management system platform to use the different features to enhance collaboration and support 
learning. They emphasized that the school administration met with them to listen to their concerns about teaching and learning online. Teachers shared with them their concerns about the anxiety of the technology use, asking for different applications (iCloud App, Google Apps, Nearpod, Miro.com, Popplet, Kahoot, etc.), change the way of students' assessments, train students as well on how to upload their written assignments, track students' progress, and teach creativity through newly designed activities. They also emphasized that the assessment structure needs to be changed to include more open-ended questions that incorporate critical thinking, reflective thinking, creation, real-life scenarios, analysis, etc., instead of focusing on factual questions.

\section{DISCUSSION AND IMPLICATIONS}

The teachers' perceptions and practices are discussed in this section using the framework to address the research questions of this study.

\section{Research Question One: What are the Teachers' Perceptions about Using the Reflective Practice Model to Plan and Teach an Integrated STEM Curriculum?}

Impressive results showed teachers' perceptions of how and why they think specific things in a certain way. Teachers highlighted that the use of technology during the quarantine of COVID-19 changed their educational perspectives. This agrees with Mezirow (1997), who pointed out that a transformation happens when changes in the frame of references occur, including points of view and habits of mind. Although students and teachers faced some difficulties in teaching and learning after the lockdown, they improved their information technology skills after replanning their educational plans. They believed that the blended learning approach would be an integral part of education due to the advantages they noticed in students' learning and teaching practices. Similar to a study of Strange \& Gibson (2017), the uncomfortable situation of the quarantine allowed for a potential change in individuals' perspectives and frames of reference.

It was explored that the higher skills of teachers and students in using technology the more efficient learning environment occurs. Teachers believed that it became essential to develop students' digital competencies during learning, even in a face-to-face learning environment. It encourages students to think critically, communicate and collaborate, and improve their understanding of problem-solving across disciplines due to the use of different software. This agrees with Owen (2016), who mentioned that critical reflection allows learners to achieve deeper meaning and understanding as they develop the sense of questioning, brainstorming, self-examination, and awareness of others are integral aspects of critical reflection. This is also consistent with Mutch's (2012) study, which confirmed the development of students' collaboration, communication, critical thinking, and creativity.

Furthermore, teachers believed that technology supported students in getting strong evidence to argue and present their ideas. This agrees with previous studies that emphasized that rational discourse occurred when meaningful communications with others in a specific dialogue intend to validate individuals' experiences and ideas (Mezirow, 1997).

Teachers highlighted that using the reflective practice model in a blended learning approach helped creates a differentiated learning environment where individual needs and goals are met. The assessments were also set as an ongoing process that improves students' learning, not evaluating them. This agrees with a study by Cheng (2015), who emphasized that teaching STEM using experiential learning allows for flexibility and differentiation of students' learning. As mentioned in a study by Almqvist et al. (2017), teachers believed that they need to restructure the instructional activities to include more resources and tools that support and enhance students' learning. This allows students to be self-reflective, independent, and critical thinkers (Li et al., 2019).

\section{Research Question Two: How Do the Reflective Model Influence Teachers' Instructional Practices?}

Teachers collaborate and communicate STEM teaching ideas together to focus on complex real-life problems. This agrees with Dugger and Fellow (2011), who represented that the most efficient way of integrating STEM is the most complex integration where there is overlap between the subjects' boundaries. The use of experiential learning occurs in project-based and problem-based learning that students used to identify the problem, formulating question(s), brainstorm alternative solutions, plan for their projects, test, and experiment, and improve their work after reflecting and receiving feedback. Students shift between divergent and convergent thinking in finding solutions to their problems and deciding the best solutions.

The teachers' focus was to design instructional activities that require students to be engaged in experiential and transformative learning. This was not confirming the result of a previous study, which stated that the teachers' focus is to raise students' achievements in standardized assessment (Dawson, 2003). However, the results agree with Strange and Gibson (2017), who emphasized the importance of designing the program and instructions using experiential and transformative learning. Teachers act as facilitators to guide and support students in their learning process, place them in homogenous groups based on their interests, etc. Students did not feel the anxiety of being assessed where 
their main goal is to complete their projects and solve the problems.

Teachers changed the teaching plans to consider teaching online after the quarantine. Teaching STEM projects online enhances students' skills such as collaboration, communication, critical thinking, creativity and innovation, use of technology and selfdirection skills. Teachers emphasized that students have been challenged with complex real-life problems. However, their most significant challenge was the quarantine that happened due to the lockdown of COVID-19. Teachers and students worked together to find alternative ways of teaching and learning. Different software was used as a way of communication where students presented their projects virtually. The use of different software and applications enhanced the teaching and learning process online. Students used eportfolios instead of journals to record their work plan and progress. Teachers scheduled meetings with students (individual/group) using Zoom conferences to do breakout rooms to meet each group to provide students with feedback on their work. They emphasized that students became more responsible and self-directed learners. This agrees with Lewis (2017), who emphasized using e-portfolio as a pedagogy for students' learning to develop their self-direction skills. The use of technology forced them to deepen their learning and find valid evidence to support their ideas and arguments.

Teachers' future plans were settled to focus more on the use of technology. They mentioned that students became independent learners, setting their own goals, and motivated to achieve their goals. This is aligned with many theorists who emphasized that transformation in students' perspectives requires them to be active learners who drive and use knowledge rather than receiving it (Dewey, 1907; Freire, 1970; Knowles, 1980).

\section{CONCLUSION AND RECOMMENDATIONS}

This study aimed to explain and explore teachers' perceptions and practices using a reflective practice model to teach STEM in a blended learning environment. The questions of the study have been addressed and confirmed the main purpose of the study. Implementing the reflective practice model in teaching STEM in a blended learning environment changed teachers' perceptions and practices. The uncomfortable situations that teachers and students face in online learning due to the quarantine changed their views of teaching STEM after COVID-19. It became essential to develop students' and teachers' digital competencies even after the quarantine. In addition, the use of the reflective model organized the instructional activities that were done in specific stages to guide students' work.

The STEM curriculum was designed to its highest level of integration, which impacted students' perspectives and how they view the world. Students felt the value of what they do in solving global problems. Teachers have a vital role in designing and planning instructional activities using many checking points that allow students to reflect on their learning critically. The results revealed that students build a relationship between their peers, community, and the world, critically reflect on their learning, actively engaged in problem-solving, change their perspectives, and engaged in sustainable community practices. The STEM curriculum required students to be engaged in an experiential learning environment (problem-based, project-based, and inquiry-based) that forced them to have several checking points to reflect on their learning and receive constructive feedback. All participants of the study emphasized the importance of students' feedback; however, teachers added that students need to get the feedback immediately as this will be more beneficial for them, and their teaching practice of modifying instructions when needed, especially after the quarantine. Students benefited from learning online as well as having face-to-face sessions; however, online learning allowed them to reach the higher-order thinking level. The STEM allowed students to experience professions and careers based on their interests, which led them to develop their creativity.

Further study about the cause-and-effect of using the reflective practice model on students' learning should be considered. Future research should be conducted to investigate the impact of students' cognitive, social/emotional, and digital engagements on developing their digital competencies. The community of inquiry model could be a model used for another area of research to ensure the presence of teaching, social, and cognitive aspects from teaching points of view and the learning presence. The correlation between students' skills developed in schools and the job market needs could be investigated. The limitation of this study implies in the fact that the lockdown forced everyone to communicate virtually.

\section{REFERENCES}

Alfaki, I. (2015). From Oil to Knowledge: Transforming the UAE into a Knowledge- based Economy. Unite Arab Emirates University UAEU. College of Business and Economics.

Almqvist, C.F. Vinage, J. Vakeva, L., \& Zanden, O. (2017). Assessmnet as learning in music education: The risk of "criteria compliance" replacing "learning" in the Scandinavian countries. Research Studies in Music Education, 39(1), 3-18. https:/ / doi.org/10.1177/1321103X16676649

Beane, J. (1991, October). The Middle School: The natural home of integrated curriculum. In Integrating the curriculum (pp. 9-13). Association for Supervision and Curreiculum Development. 
Beard, C. M., \& Wilson, J. P. (2006). Experiential Learning: A Best Practice Handbook for Educator and Trainers (2nd ed.). London: Kogan Page.

Cheng, V. M. Y. (2015). Assessment for creative teaching and learning. In The Routledge International Handbook of Research on Teaching Thinking (pp. 330343). Routledge International Handbooks. London and New York: Routledge, Taylor \& Francis Group.

Cranton, P., Carusetta, E. (2004). Perspectives on authenticity in teaching. Adult Education Quarterly, 55(1), 5-22. https:/ / doi.org/10.1177/074171360426 8894

Creswell, J. (2014). Research design. Qualitative, Quantitative E Mixed Methods Approaches. Thousand Oaks, California: Sage Publications.

Dawson, C. (2003). Writing and teaching as creative processes: Helping students and teachers develop voice and agency through writing and professional development. Keynote speech delivered as Middlesex County Teacher of the Year at the Middlesex County Superintendent's Roundtable. Middlesex County, NJ.

Dewey, J. (1907). Waste in Education. In The School and Society (Chapter 3, pp. 77-110). Chicago: University of Chicago Press.

Dewey, J. (1933). How we think: A restatement of the relation of reflective thinking to the educative process. Lexington, MA: D. C. Heath and Company.

Dewey, J. (1938). Experience and Education. New York, H. Holt and Company.

Dubai Future Foundation. (2020). Life After COVID-19 (pp. 1-6). Dubai: Dubai Future Foundation.

Dugger, W., \& Fellow, J. (2011). Evolution of STEM in the United States [Paper presentation]. 6th Biennial International Conference on Technology Education Research, Surfers Paradise, Queensland, Australia. Retrieved on 21 January 2019 from http:/ / www.iteea.org/Resources/PressRoom/Au straliaPaper.pdf

ElSayary, A. (2020). Transforming Students' Learning through Transdisciplinary STEAM Curriculum Design. In S. A. David \& C. Hill (Eds.), Curriculum Innovation and Transformation: Studies on Design, Discourse and Development (pp. 5-32). Beau Bassin: Scholar's Press.

ElSayary, A., Forawi, S., \& Mansour, N. (2015). Teaching thinking in STEM subjects: STEM education and problem-based learning. In The Routledge International Handbook of Research on Teaching Thinking (pp. 357-368). Routledge International Handbooks. London and New York: Routledge, Taylor \& Francis Group.

Freire, P. (1970). Pedagogy of the oppressed. New York: Herder and Herder.
Greenhill, J. Richards, J. N. Mahoney, S. Campbell, N., \& Walters, L. (2018). Transformative Learning in Medical Education: Context Matters, a South Australian Longitudinal Study. Journal of Transformative Education, 16(1), 58-75. https:/ / doi.org/10.1177/1541344617715710

Guyotte, K. W. Sochacka, N. W., Walther, J., \& Kellam, N. N. (2014). STEAM as social practice: Cultivating creativity in transdisciplinary spaces. Art Education, 67(6), 12-19. https://doi.org/10.1080/00043125. 2014.11519293

Handal, B., Campbell, C., Cavanagh, M., Petocz, P., \& Kelly, N. (2013). Tecnological Pedagogical Content Knowledge of secondary mathematics teachers. Contemporary Issues in Technology and Teacher Education, 13(1), 22-40.

Hvidt, M. (2016). Challenges to implementing 'Knowledge based economies' in the Gulf region. Center for Mellemoststudier. Syddansk Universitet. Retrieved from https://www.sdu.dk/-/media/ files/om_sdu/centre/c_mellemoest/videncenter/ artikler/2016/hvidt+article+(sept+16).pdf

Johnson, B. and Christensen, L. (2014). Educational research: Quantitative, Qualitative, and Mixed-method (5th ed.). Los Angeles: Sage Publications.

Knowles, M. (1980). The Modern Practice of Adult Education. Chicago: Associated Press.

Kolb, D. (1984). Experiential Learning: Experience as the source of Learning and Development. Englewood Cliffs, NJ: Prentice-Hall.

Lewis, L. (2017). ePortfolio as pedagogy: Threshold concepts for curriculum design. E-Learning and Digital Media, 14(1-2), 72-85. https://doi.org/ $10.1177 / 2042753017694497$

Li, H., Ochsner, A., \& Hall, W. (2019). Application of experiential learning to improve student engagement and experience in a mechanical engineering course. European Journal of Engineering Education, 44(3), 283-293. https:/ / doi.org/10.1080/ 03043797.2017.1402864

Mann, K., Gordon, J., \& MacLeod, A. (2007). Reflection and reflective practice in health professions education: a systematic review. Advances in Health Science Education, 14(4), 595-621. https://doi.org/ 10.1007/s10459-007-9090-2

Merriam, S. B. (2004). The role of cognitive development in Mezirow's transformational learning theory. Adult Education Quarterly, 55, 60-68. https:/ / doi.org/10.1177/0741713604268891

Mezirow, J. (1997). Transformative learning: theory to practice. New Dir Adult Cont Educ., (74), 5-12. https:/ / doi.org/10.1002/ace.7401

Moonesar, I., Mourtada, R., Shaer, S., Al-Eisawi, D., \& Elomari, L. (2015). Persistence in the Abu Dhabi STEM Pipeline. Preparing Emirati Youth for Science 
and Technology Careers in The Innovation Economy. Mohamed Bin Rashid School of Government. Dubai, United Arab Emirates.

Mutch, C. (2012). Assessment for, of and as learning: developing a sustainable assessment culture in New Zealand schools. Policy Future in Education, 10(4), 374-385. https://doi.org/10.2304/pfie.2012. 10.4 .374

National Research Council. (2000). How people learn: Brain mind, experience, and school. Washington: National Academy Press.

Owen, L. (2016). Critical Reflection on Practice Development. Emerging from physiotherapy practice, masters-level education and returning to practice: a critical reflection based on Mezirwo's transformative learning theory. International Practice Development Journal, 6(2), 1-9. https://doi.org/10.19043/ipdj.62.011

Provident, I., Salls, J., Dplhi, C., Schreiber, J., Mattila, A., \& Eckel, E. (2015). Design an Online Curriculum Promoting Transformative Learning in Post Professional Doctoral Students. Online Learning Volume, 19(3), 128-143. https://doi.org/10.24059/ olj.v19i3.526

Repko, A. (2008). Interdisciplinary research (1st ed.). Los Angeles: SAGE.

Singleton, J. (2015). Head, heart and hands model for transformative learning: Place as context for changing sustainability values. Journal of Sustainability Education, 9. Retrieved from http://www.jsedimensions.org/wordpress/wpcontent/uploads/2015/03/PDF-Singleton-JSEMarch-2015-Love-Issue.pdf

Sipos, Y., Battisti, B., \& Grimm, K. (2008). Achieving transformative sustainability learning: Engaging head, hands and heart. International Journal of Sustainability in Higher Education, 9, 68-86. https:/ / doi.org/10.1108/14676370810842193

So, H. J., Ryoo, D., Park, H., \& Choi, H. (2018). What constitutes Korean pre-service teachers' competency in STEAM education: Examining the multi-functional structure. The Asia-Pacific Education Researcher, 28, 47-61. https:/ / doi.org/10.1007/s40299-018-0410-5

Strange, H., \& Gibson, H. (2017). An investigation of experiential and transformative learning in study abroad programs. Frontiers: The Interdisciplinary Journal Of Study Abroad, 29(1), 85-100. https:/ / doi..org/10.36366/ frontiers.v29i1.387

Taylor, E. W. (2007). An update of transformative learning theory: A critical review of the empirical research (1999-2005). International Journal of Lifelong Education, 26, 173-191. https://doi.org/10.1080/ 02601370701219475

Taylor, E. W. (2016). Research Conference 2016: Improving STEM Learning, What will it take? Australian Council for Educational Research.

UAE Government. (2015). Science, Technology and Innovation Policy in the United Arab Emirates ( $1^{\text {st }} \mathrm{ed}$.).

UAE National Committee on SDGs (2017). UAE and the 2030 Agenda for Sustainable Development: Excellence in Implementation. Retrieved from https://sustain abledevelopment.un.org/content/documents / 201 61UAE_SDGs_Report_Full_English.pdf

UAE Vision 2021 (2009). Vision 2021: United in Ambition and Determination. Abu Dhabi: United Arab Emirates. Retrieved from http://www.vision2021. ae

\section{http://www.ejmste.com}

